\title{
The study of serum and tissue cholesterol levels in children undergoing tonsillectomy
}

\author{
M. Shaaker ${ }^{1}$, A. Mehdizadeh², R. Ezzeddini ${ }^{3}$, B. Ghasemi ${ }^{4}$, Y. Jabbari Moghaddam ${ }^{5}$, Sh. Abdollahi Fakhim ${ }^{5}$, \\ M. Saleh Moghaddam ${ }^{6}, \underline{\text { M. Darabi }}^{7}$
}

\author{
${ }^{1}$ Department of Biochemistry and Clinical Laboratories, Faculty of Medicine, Tabriz University of Medical Sciences, \\ Tabriz, Iran \\ ${ }^{2}$ Endocrine Research Center, Tabriz University of Medical Sciences, Tabriz, Iran \\ ${ }^{3}$ Department of Clinical Biochemistry, Faculty of Medicine, Tarbiat Modares University, Tehran, Iran \\ ${ }^{4}$ Division of Pathology, Tabriz Children's Hospital, Tabriz University of Medical Sciences, Iran \\ ${ }^{5}$ Department of Otolaryngology, Head and Neck Surgery, Tabriz University of Medical Sciences, Tabriz, Iran \\ ${ }^{6}$ Department of Biology, Faculty of Sciences, Payame Noor University of Mashhad, Mashhad, Iran \\ ${ }^{7}$ Tuberculosis and Lung Research Center, Tabriz University of Medical Sciences, Tabriz, Iran \\ Corresponding Address: Masoud Darabi, Tuberculosis and Lung Research Center, Tabriz University of Medical Sciences, \\ Glogasht Ave., Tabriz, Iran \\ Tel: +98-41-33364666; Email: darabim@tbzmed.ac.ir \\ Received: 18 Apr 2018; Accepted: 22 Sep 2018
}

\section{*bstract}

Background: Inflammatory and obstructive tonsillar diseases are among the most common diseases in childhood, and tonsillectomy is one of the most common surgical procedures in children. Current evidence indicates the potential association between cholesterol and inflammation.

Objective: The aim of this study was to determine the levels of serum and tissue cholesterol in children undergoing tonsillectomy by gas-liquid chromatography.

Methods: Eighty six children with an average age of $7.02 \pm 0.24$ who referred to Tabriz Children's Hospital were studied with signs of infection and large tonsils. Tonsillectomy was performed and tissues were evaluated by using hematoxylin-eosin technique. The sampling process lasted for one year from February 2010 to 2011. Patients were divided in two groups of hyperplasia $(n=48)$ and chronic tonsillitis $(n=38)$. The cholesterol content of serum and tonsillar tissues were extracted and measured by gas-liquid chromatography.

Findings: There was no significant difference in serum cholesterol between the two groups $(\mathrm{P}=0.32)$. However, the tonsillar cholesterol level in the chronic tonsillitis group was higher than the hyperplasia group $(\mathrm{P}=0.038)$. In the chronic tonsillitis group, the level of tissue cholesterol in the pathological grade 4 was significantly higher than other grades $(\mathrm{P}=0.009)$.

Conclusion: The level of tissue cholesterol in children with chronic tonsillitis was higher than those with tonsillar hyperplasia and this level was higher in tonsillitis with higher pathological grade.

Keywords: Cholesterol, Gas chromatography, Tonsil, Tonsillectomy, Hyperplasia, Children Citation: Shaaker M, Mehdizadeh A, Ezzeddini R, Ghasemi B, Jabbari Moghaddam Y, Abdollahi Fakhim Sh, Saleh Moghaddam M, Darabi M. The study of serum and tissue cholesterol levels in children undergoing tonsillectomy. J Qazvin Univ Med Sci 2018; 22(4): 4-12. 


\title{
بر رسى ميزان كلسترول سرمى و بافتى در كودكان تحت جراحى برداشت لوزه
}

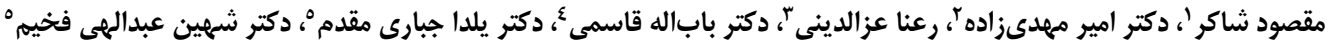

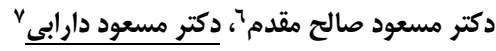

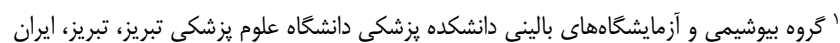

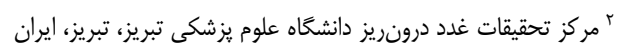

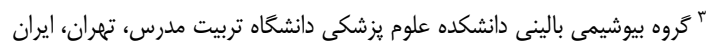

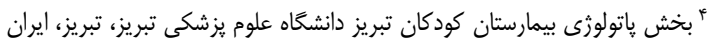

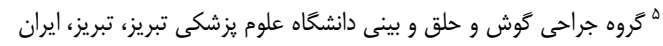

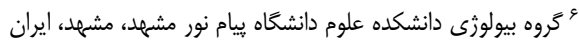

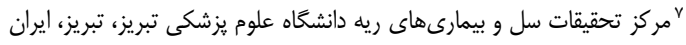

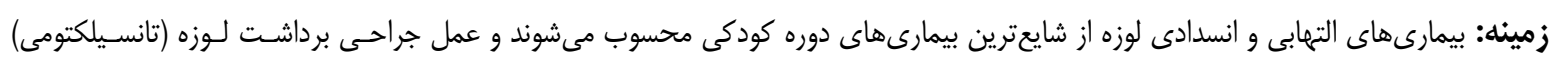

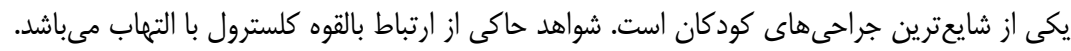

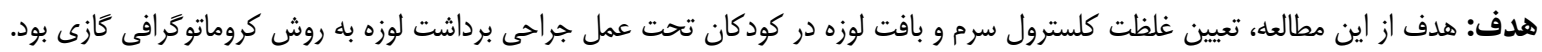

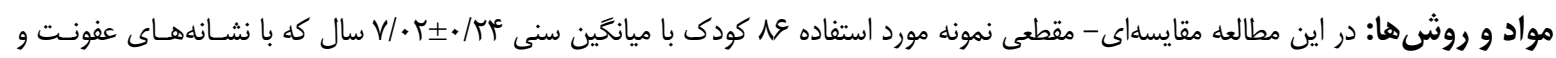

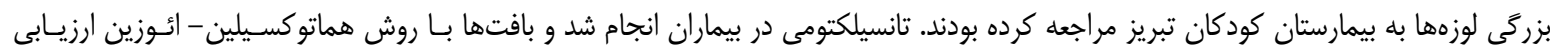

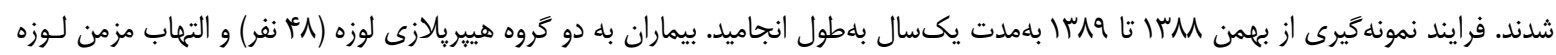

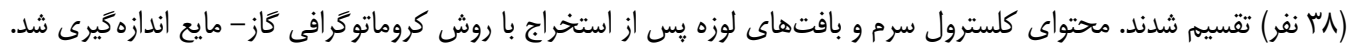

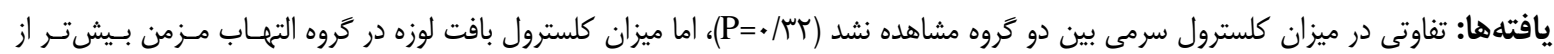

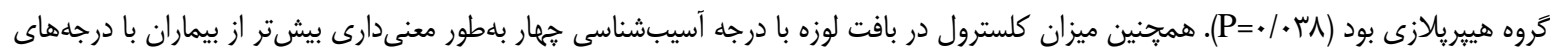

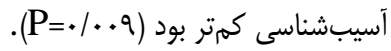

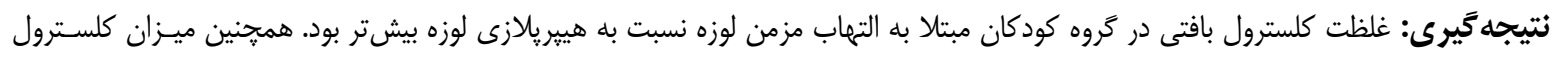

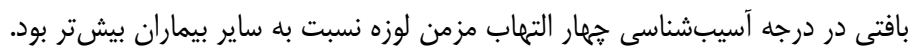
كليدوازهها: كلسترول، كاز كروماتوكرافى، لوزه، برداشت لوزه، هييريازى، كودكان

آزمايشگاهى، كشت بافت لوزه در كنار برخى بـاكترىهـا

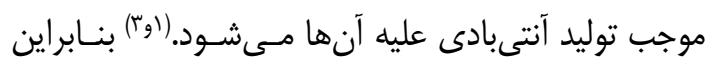

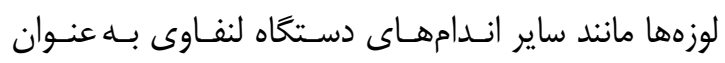
بخشى از دستخاه ايمنى بلدن بوده كه در مقابله با عفونتها

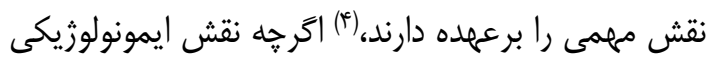

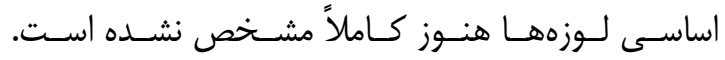

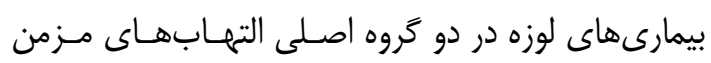

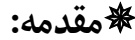

لوزهها تودههايى از بافت لنفاوى همراه با موكوس بوده

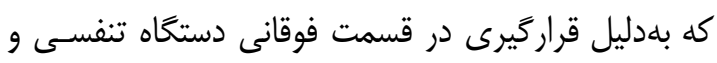

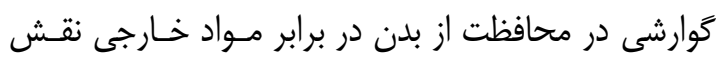

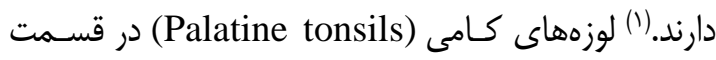
يشتى كلو قرار دارند و حاوى تعداد زيادى لنفوسـيتهـاى

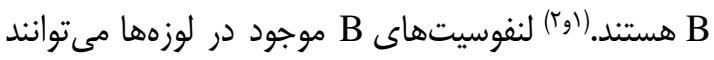

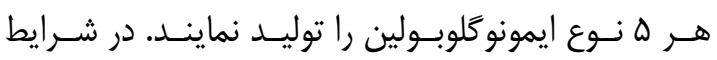


باكترىها مانند هليكوباكتر ييلورى عمـل مسى كنتـد.(ه)| (ز طرفى برخى از عوامل بيمارىزا بـا اسـتفاده از كلسـترول

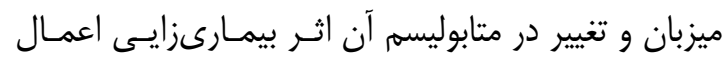
مى كنند. (19) كاهش در كلسترول لنفوسيتهـا، بـهـعنـوان يكـى از اصلىترين سلولهـا در عملكـرد لـوزههـا، موجـب مهـار

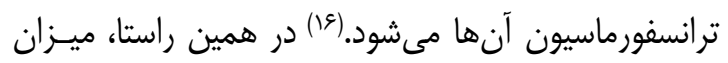

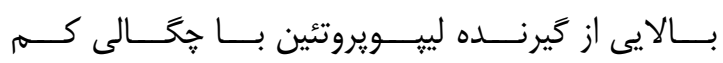
(Low-density lipoproteins; LDL) لنفوسيتهاى لوزه مشاهده شده اسـت كـه نشـان دهنـــه

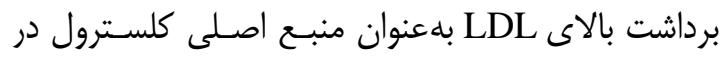

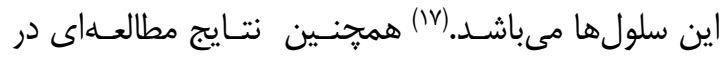

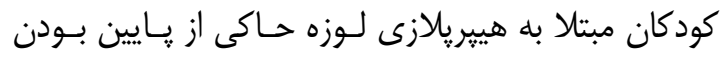
سـطح سـرمى كلسـترول-HDL در ايـن بيمـاران بـوده

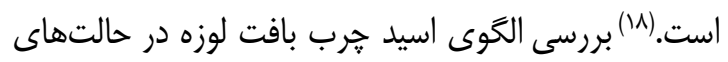

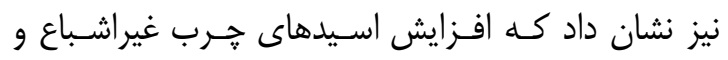
احتمال افزايش يراكسيداسيون لييبيدى در خطـر ابـتلا بــه عفونت لوزه سهيم است. (9.و-r)

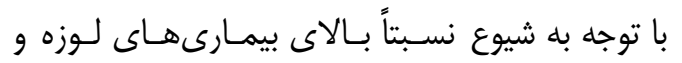

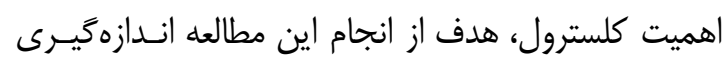

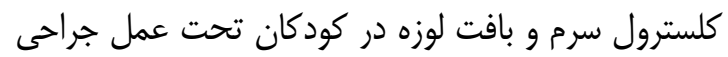

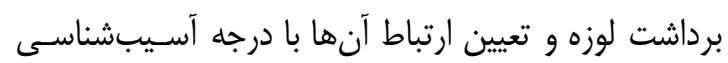
التهاب مزمن يا هييريلازى لوزه بود.

\section{نمواد و روشها:}

نمونههاى مورد استفاده در اين مطالعه طى مطالعههاى

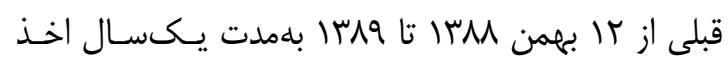

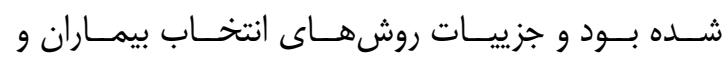

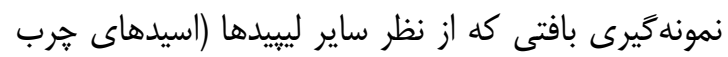

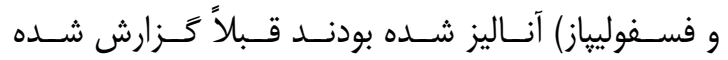

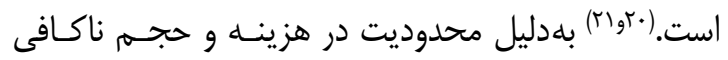

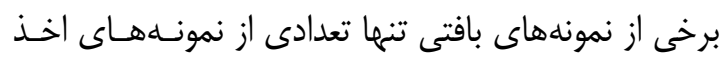

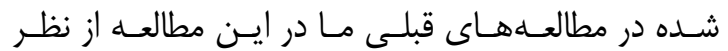
كلسترول آناليز شد.
(تانسيليت) و هييريالازى لوزه قرار مى گيرند. در گروه اول،

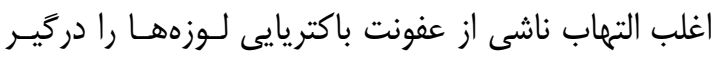

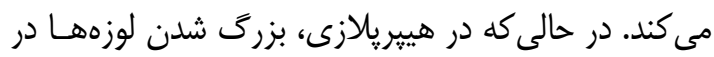

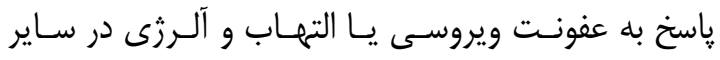

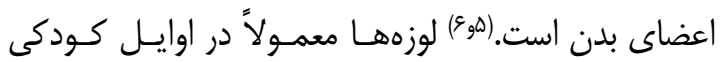

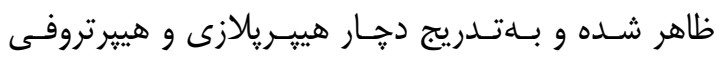

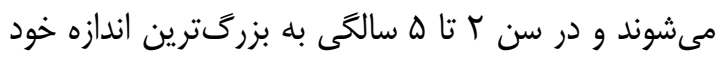

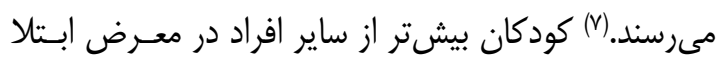

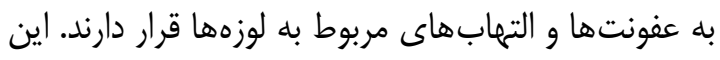

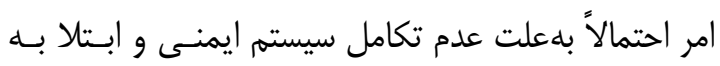

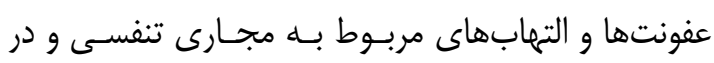

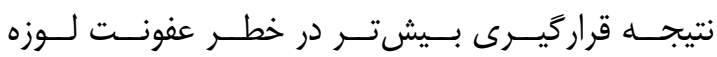

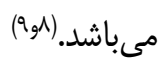
بيمارىهاى لوزه اصلىترين علت كمخوابى در نوزادان و ل VD درصد از موارد آينه تنفسى (Sleep apnea) حسين

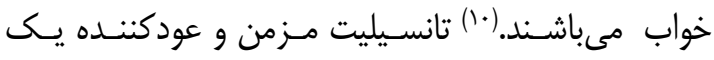

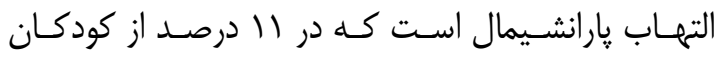

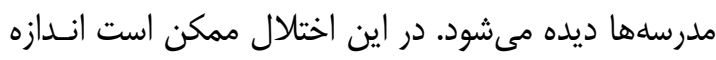

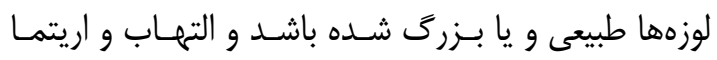

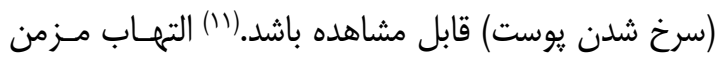

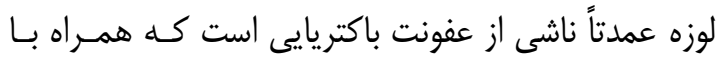

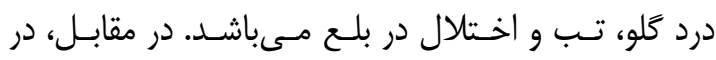

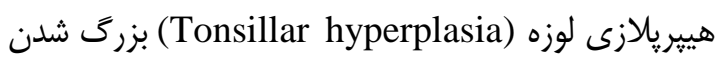

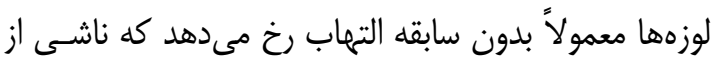

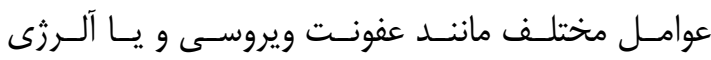
مىباشد. موامل مختل براساس يكى مطالعه آمـارى كـهـ توسـط عزالــدينى و

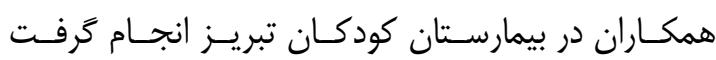

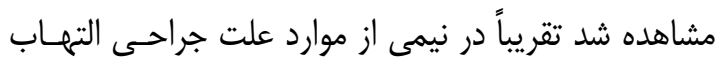

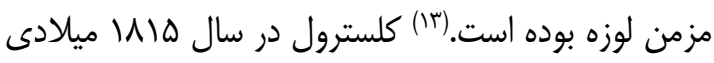

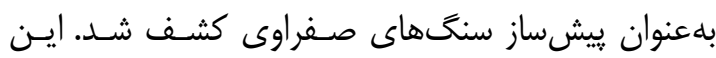

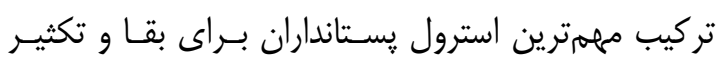

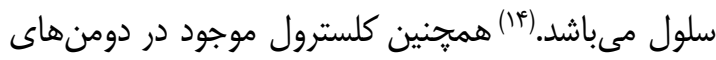

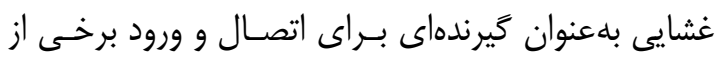


ڤاتولوزيست بـاتجربـهـ بررسـى شـــ. روايسى دسـتهبنـدى

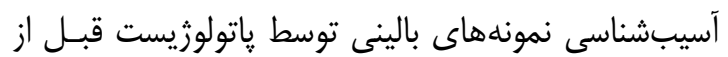

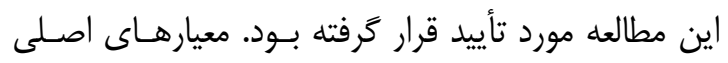

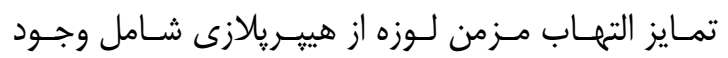
لنفوسيت منتشر و نقص در اييتليوم بود.

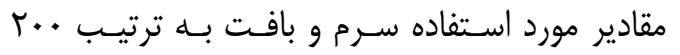

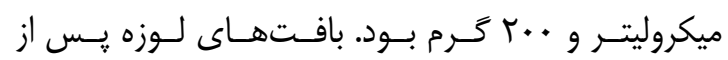

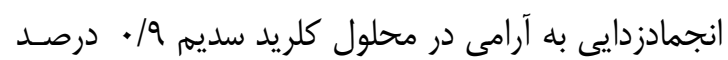

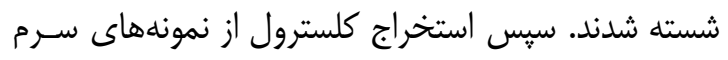

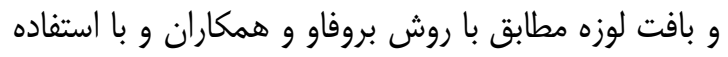

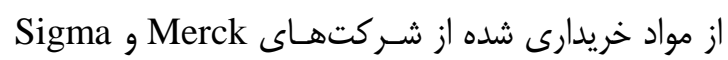

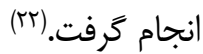

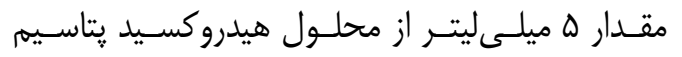

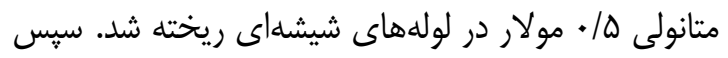

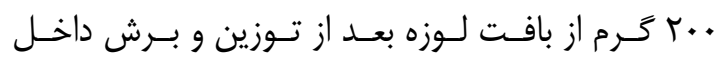

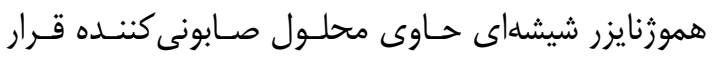

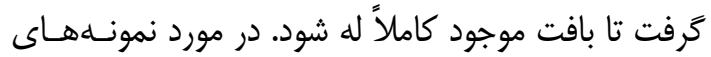
سرمى، محتويات لوله بلهمـدت ها ثانيـهـ در شـيكر كـاملاً

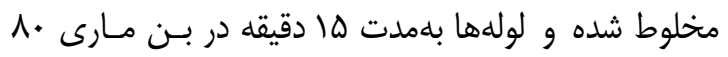

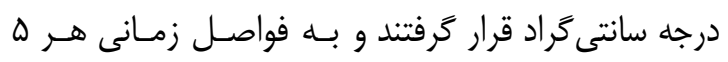

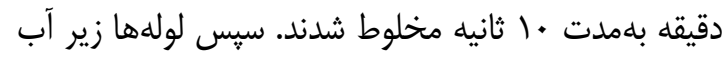

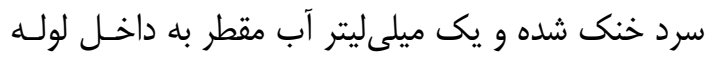

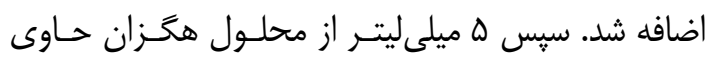

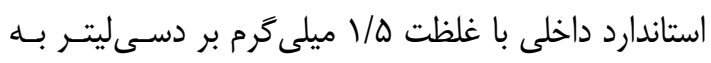
داخل لوله اضافه شد و بلهمدت يك دقيقه محتويـات لولهـ

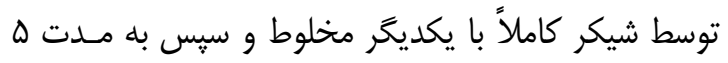

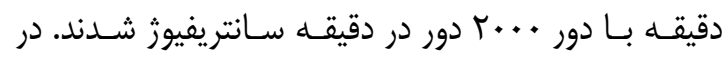

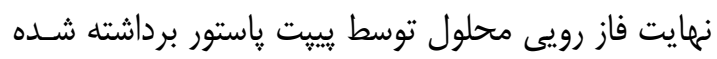

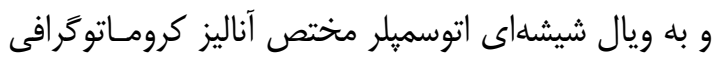
كازى منتقل شدند. آناليز مشتقات استخراج شده كلسترول توسط دسـتخاه كاز كروماتو گرافى مدل Buck Scientific 610 (USA) مجهز به دتكتور يونيزاسيون شعلهاى و ستون مويينـه بـهـ

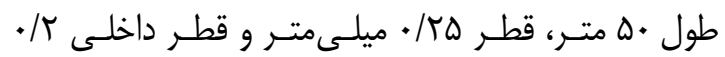

در اين مطالعه مقطعى بلصورت مقايسـاى عم بيمـار

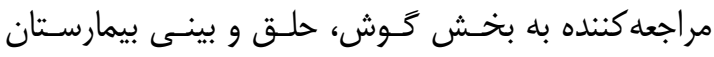

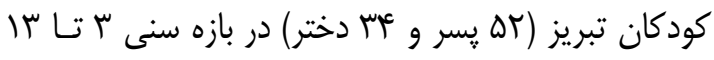

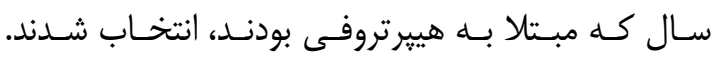

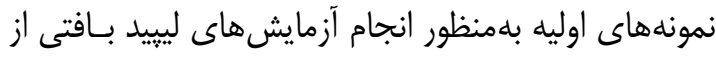

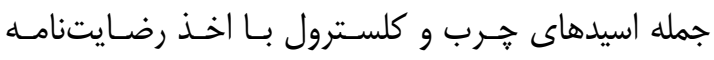

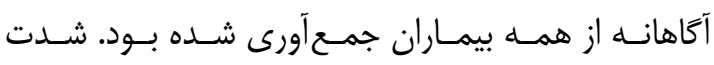

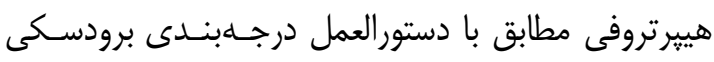

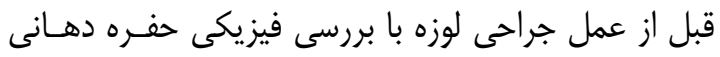

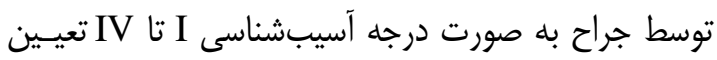

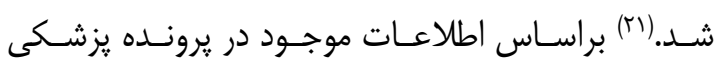

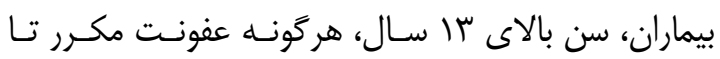

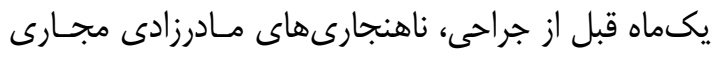

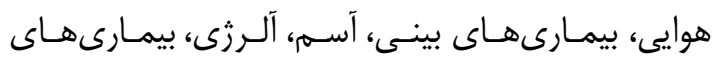

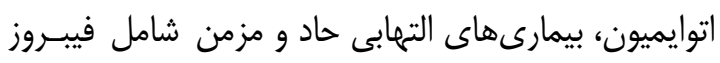

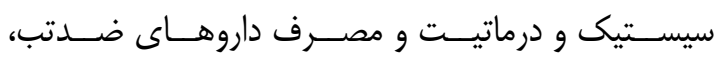

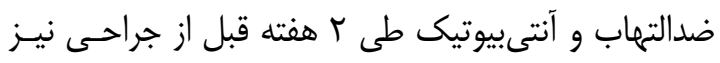

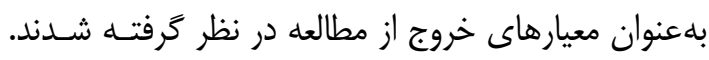

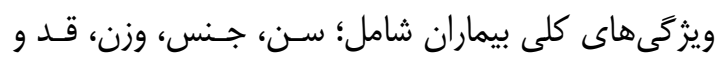

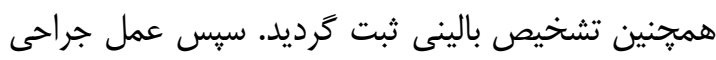

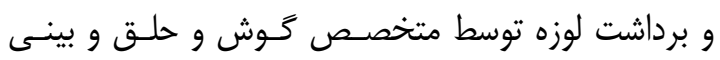

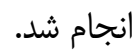
جهت بررسى ميزان كلسترول سرم از همه افراد مورد

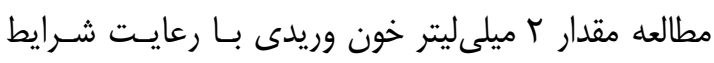

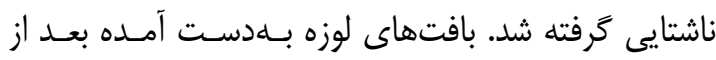

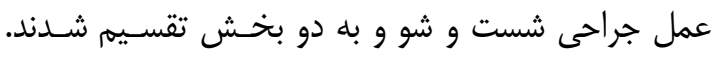

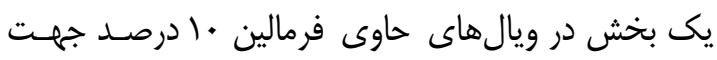

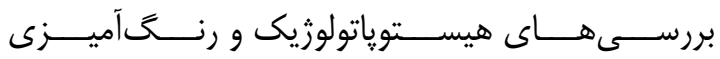

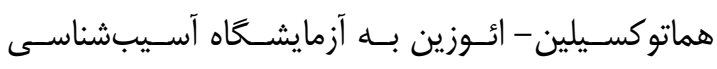

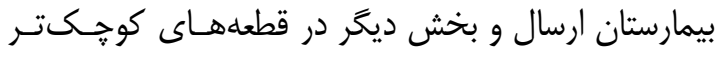

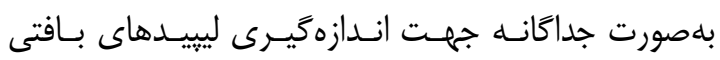

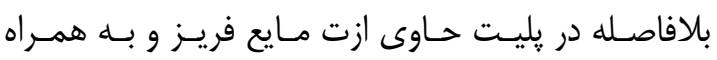

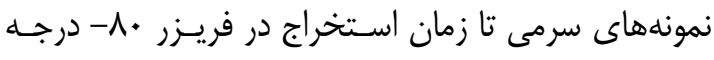

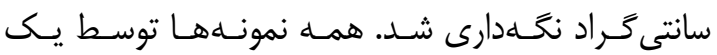




\section{جدول ( - ويزَّى هاى جمعيتشناختى و فراوانى نوع بيمارى لوزه در جمعيت مورد مطالعه (n=17)}

\begin{tabular}{|c|c|}
\hline 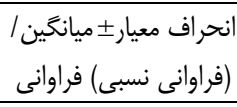 & شاخص \\
\hline$V / \cdot T \pm \cdot / T L^{2}$ & سن (سال) \\
\hline$m e(\cdot / r q)$ & جنس (دختر) \\
\hline $\mid Q / \Lambda F \pm \cdot / \Gamma \Delta$ & شاخص توده بدنى (كيلوكرم بر مترمربع) \\
\hline$\uparrow \wedge(\cdot / \Delta s)$ & هييريالزى (تعداد) \\
\hline 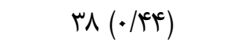 & التهاب مزمن لوزه (تعداد) \\
\hline & درجه آسيبشناسى توده لوزه (تعداد) \\
\hline$f(\cdot / \cdot \theta)$ & I \\
\hline If $(\cdot / 19)$ & II \\
\hline س & III \\
\hline$r \Delta(\cdot / 4 \mid)$ & IV \\
\hline
\end{tabular}

اعداد داخل يرانتز فراوانى نسبى دادهاى كيفى را نشان مىهد.

غلظت كلسترول سرم و بافت لوزه در بيماران مبتال به

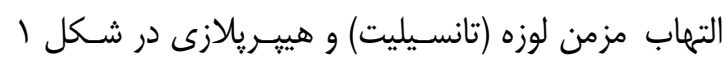

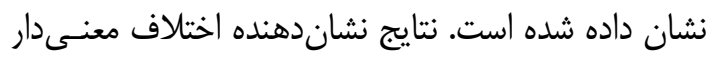
در ميزان كلسترول بافتى كودكان مبتلا به التهاب مـزمن

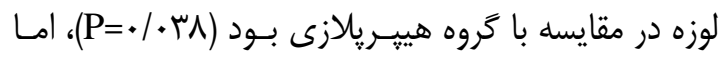

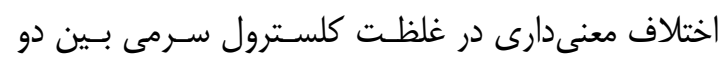
كروه مورد مطالعه مشاهده نشد (Tس/. P= (P=).

\section{نمودار ( - غلظت كلسترول سرمى و بافتى در دو تروه

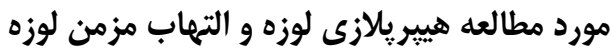
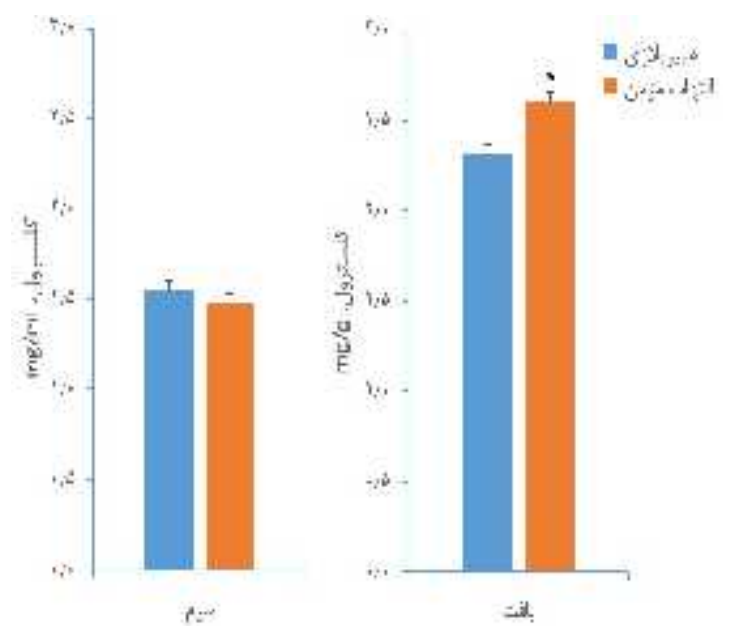

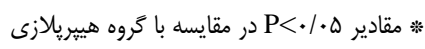

ميكرومتـــــ (TRB-Esterol, Teknokroma, Spain)

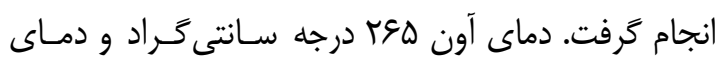

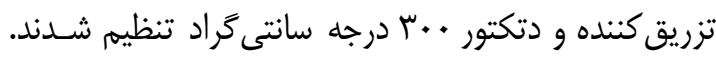

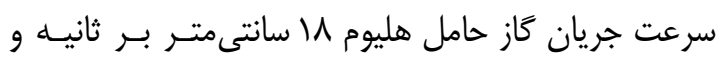
حجم نمونه تزريقى ا ميكروليتر بود. محتـواى كلسـترول

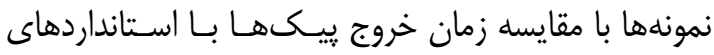

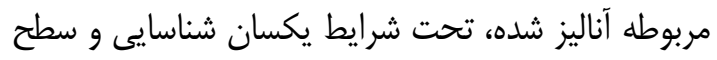

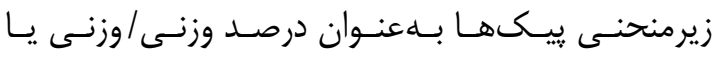

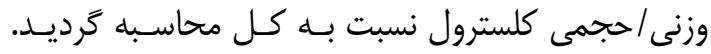

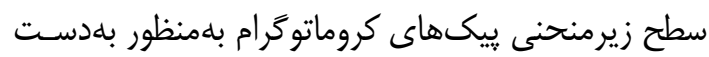

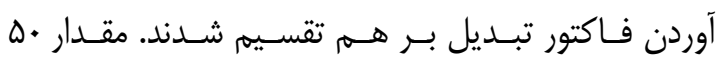

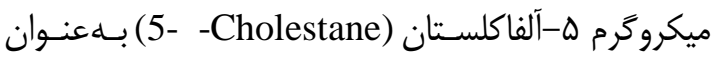
استاندارد بهازاى هر ميكروليتر نمونه تزريقى بود. در نتيجه

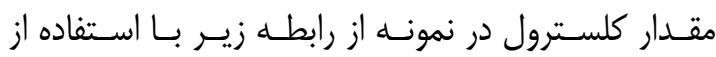
كروماتو گرام توسط نرمافزار دستخاه بلهدست آمدا:

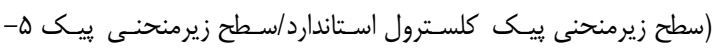
F آلفاكلستان) =(ضريب استاندارد)

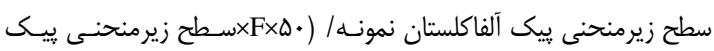

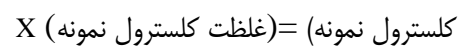

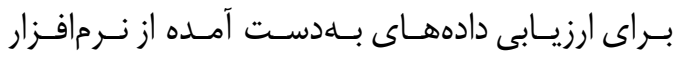

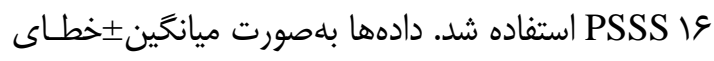

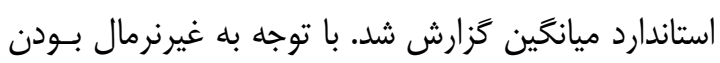

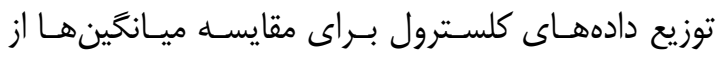
آزمون غيريارامترى من ويتنسى يـو در سـطح معنسى دارى

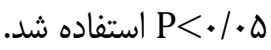

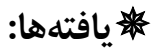

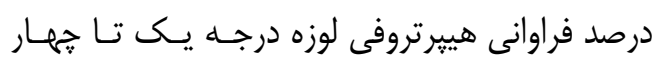

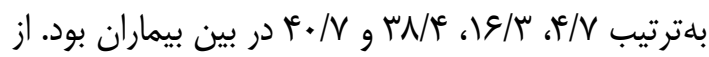

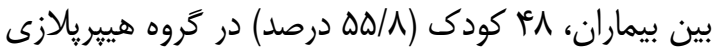

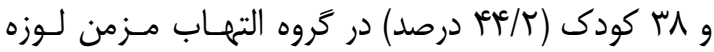

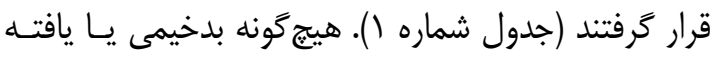
پاتولوزيك غيرمعمول در نمونههاى بررسى شده مشـاهده 
مزمن لوزه بيشتر از بيماران مبـتلا بــه هيـريـازى لـوزه

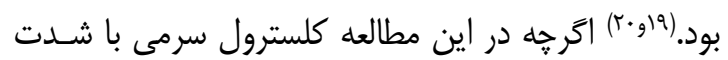

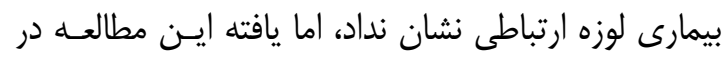

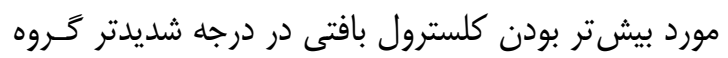

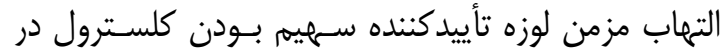
شدت بيمارى التهاب ناشى از عفونت مزمن باكتريايى لوزه است.

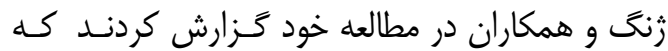
تفاوت معنىدارى از نظر تعداد فوليكول ها بين افراد مبـتلا

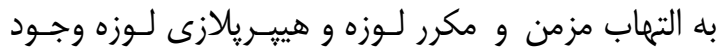

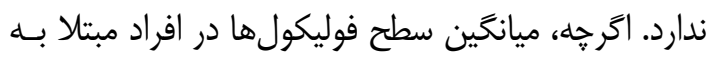

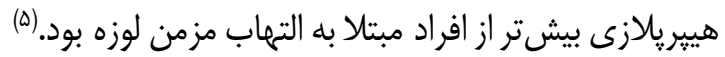
همجِنين مقايسه ميزان كلسترول تام سـرمى در دو گـروه

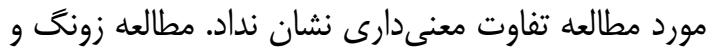

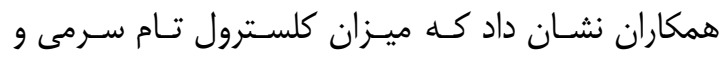

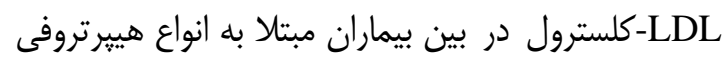

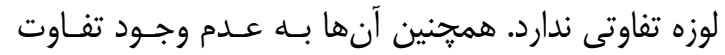

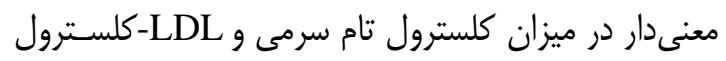

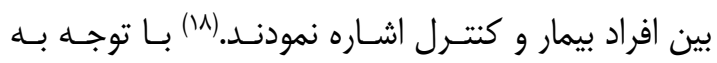

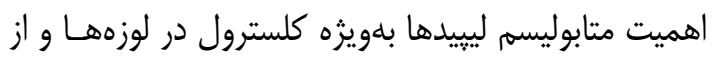
طرفى نتايج مطالعه حاضر و مطالعههـاى قبلى مسىتـوان

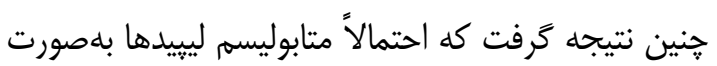

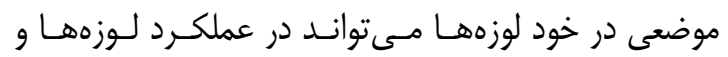

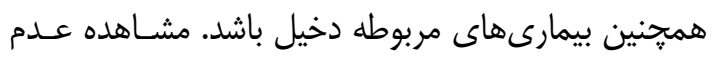
ارتباط بين كلسترول سرمى و درجه بيمارى در افراد مبتلا

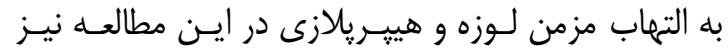

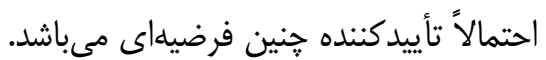

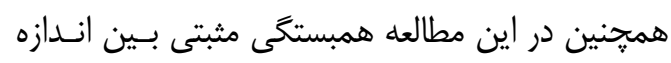

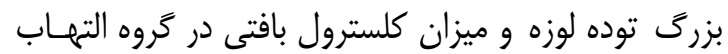
مزمن لوزه ديده شد كه احتمال دخالت كلسترول در ميزان ييشرفت بيمارى را مطرح مسىسـازد. ارتبـاط بـين ميـزان

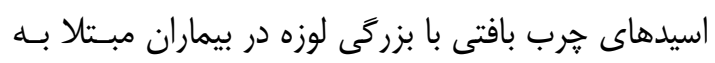

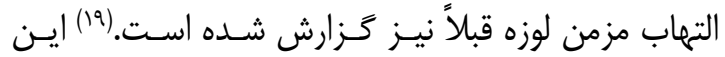
مطالعه نشان داد كه ميزان كلسترول بافتى در لـوزه افـراد

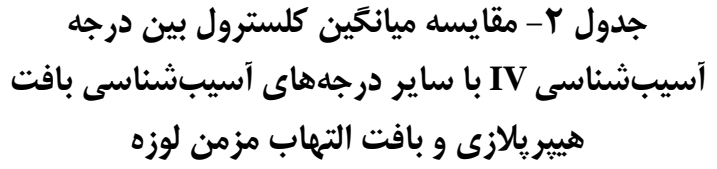

\begin{tabular}{|c|c|c|c|}
\hline \multirow{2}{*}{ معنى دارى } & \multicolumn{2}{|c|}{ درجه آسيبشناسى } & \\
\hline & IV & III تا I I & \\
\hline & $n=r 1$ & $n=r r$ & كروه هيبريلازى \\
\hline$\cdot / D F$ & $1 / \Delta r \pm \cdot 1 \cdot 9$ & $1 / \Delta \% \pm \cdot 1 \cdot 9$ & كلسترول سرمى \\
\hline$\cdot / \Delta V$ & $r / r r \pm . / / r$ & $r / r q \pm \cdot / \cdot 1$ & كلسترول بافتى \\
\hline & $\mathrm{n}=11 \mathrm{f}$ & $\mathrm{n}=r r^{2}$ & كروه التهاب مزمن \\
\hline .1 .9 & $1 / \mu F \pm \cdot / 11$ & $1 / \Delta \Delta \pm \cdot / \cdot \Delta$ & كلسترول سرمى \\
\hline $.1 . .9 *$ & $r / 9 \varepsilon \pm \cdot / / f$ & $r / 4 \cdot \pm \cdot / T$ & كلسترول بافتى \\
\hline
\end{tabular}

* مقادير ه./P مر مقايسه با گروه هييريلازى

مطابق با جدول شـماره ז، مقايسـه ميـانخين هـر دو

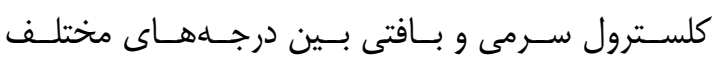

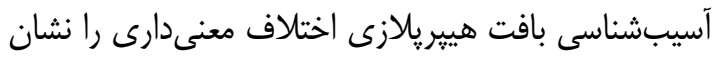

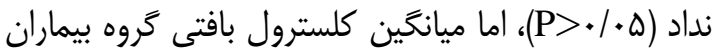

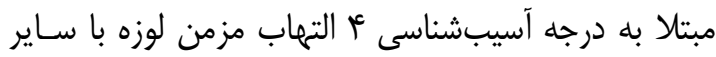

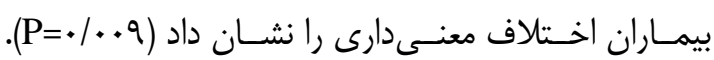

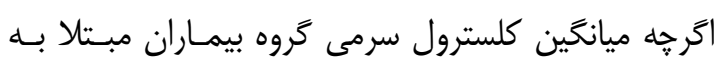

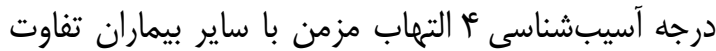

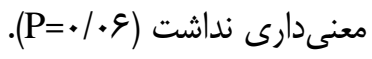

\section{بحث و نتيجه كيرى:}

براساس يافتـهـهـاى ايـن مطالعـه، ميـزان كلسـترول

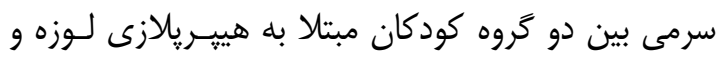

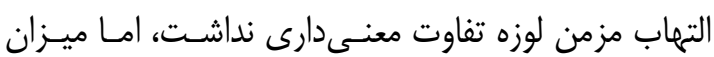
كلسترول بافت لوزه در گروه التهاب مزمن بيشتر از كروه هييريالازى بود. همجنين ميزان كلسترول در بافت لوزه بـا

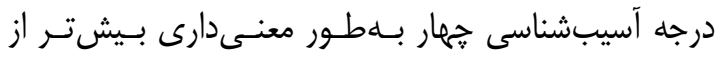
كروههايى با درجه آسيبشناسى يك، دو و سها بهاس بود.

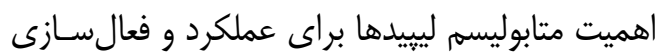

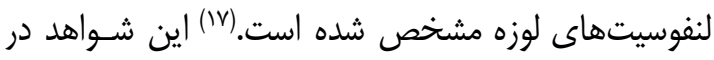

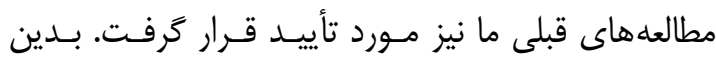

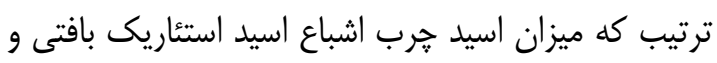

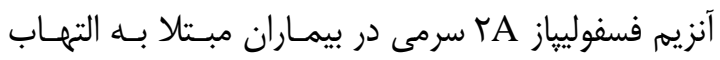


نقاط ضعف مطالعه حاضر، فقدان گروه كنتـرل سالـمر بـود

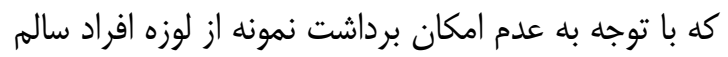
قابل توجيه است.

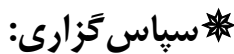

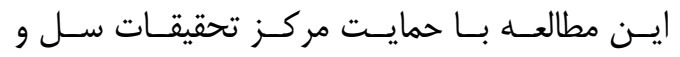

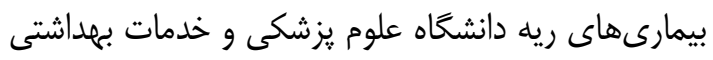

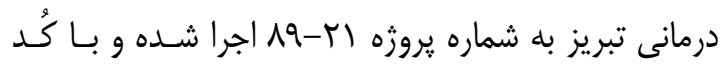

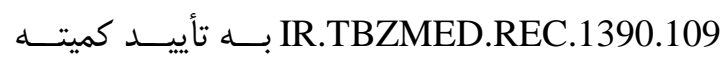

$$
\text { اخلاق دانشعاه علوم يزشكى تبريز رسيد. }
$$

\section{مراجع:}

1. Suzumoto M, Hotomi M, Fujihara K, Tamura S, Kuki K, Tohya K, et al. Functions of tonsils in the mucosal immune system of the upper respiratory tract using a novel animal model, Suncus murinus. Acta Otolaryngol 2006; 126(11): 1164-70. doi: 10. 1080/00016480600681593.

2. Nave H, Gebert A, Pabst R. Morphology and immunology of the human palatine tonsil. Anat Embryol (Berl) 2001; 204(5): 367-73.

3. Geißler K, Markwart R, Requardt RP, Weigel C, Schubert K, Scherag A, et al. Functional characterization of $\mathrm{T}$-cells from palatine tonsils in patients with chronic tonsillitis. PLoS One 2017; 12(9): e0183214. doi: 10.1371/journal.pone.0183214.

4. Lange MJ, Lasiter JC, Misfeldt ML. Tolllike receptors in tonsillar epithelial cells. Int $\mathbf{J}$ Pediatr Otorhinolaryngol 2009; 73(4): 61321. doi: 10.1016/j.ijporl.2008.12.013.

5. Zhang PC, Pang YT, Loh KS, Wang DY. Comparison of histology between recurrent tonsillitis and tonsillar hypertrophy. Clin Otolaryngol Allied Sci 2003; 28(3): 235-9. doi: 10.1046/j.1365-2273.2003.00697.x.

6. Just T, Gafumbegete E, Gramberg J, Prüfer
مبتلا به التهاب مزمن نسبت به گَروه هييريلازى بيشتر

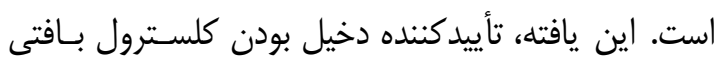

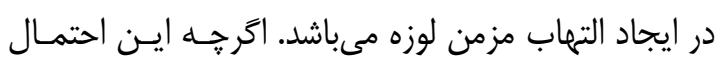

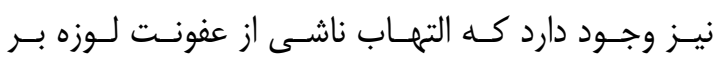

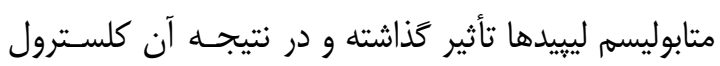

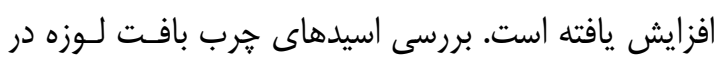

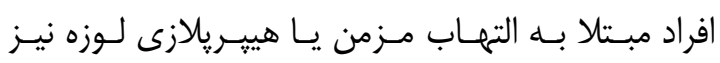

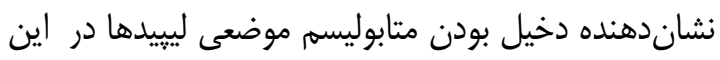
بيمارى هاى لوزه بود.(19) كلسترول و اسيدهاى خرب اشباع تشكيل دهنده ساختار

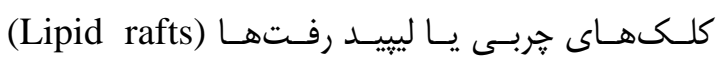

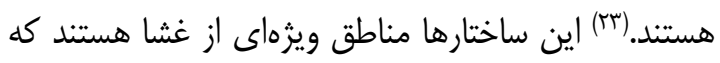

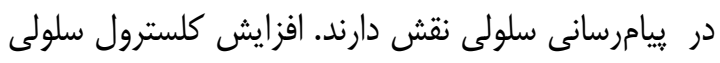

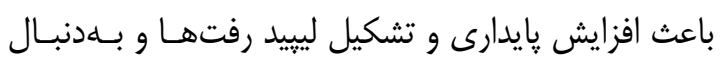

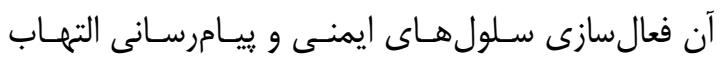

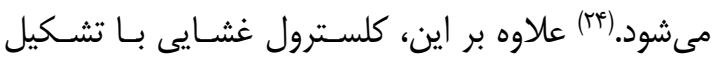

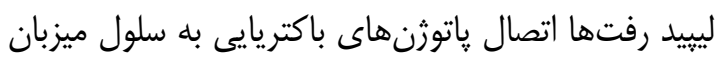

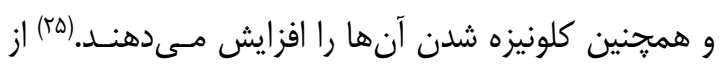

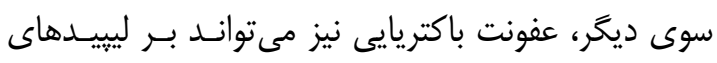

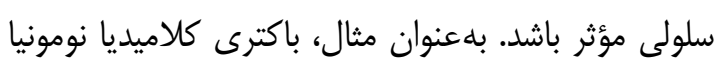

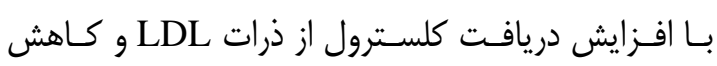

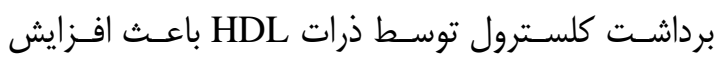
محتواى سلولى كلسترول مىشود.(19)

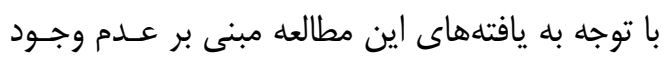

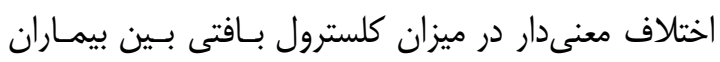

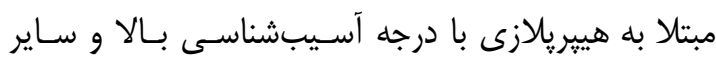

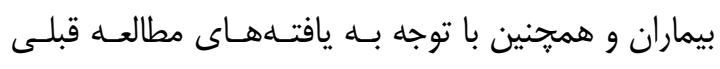

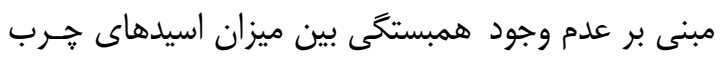

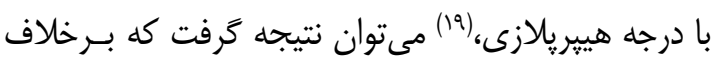

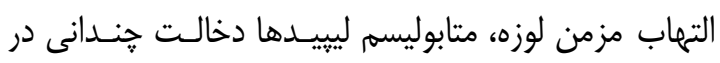

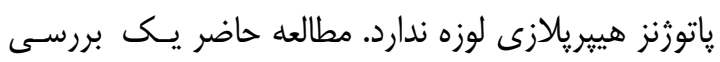

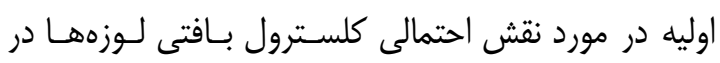

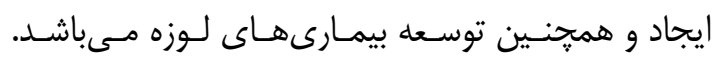

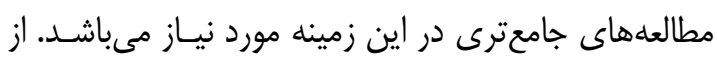


I, Mikkat S, Ringel B, et al. Differential proteome analysis of tonsils from children with chronic tonsillitis or with hyperplasia reveals disease-associated protein expression differences. Anal Bioanal Chem 2006; 384(5): 1134-44. doi: 10.1007/s00216-0050288-y.

7. Hong HS, Lee JY, Jeong SH. Normative values for tonsils in pediatric populations based on ultrasonography. J Ultrasound Med 2018; 37(7): 1657-63. doi: 10.1002/jum. 14513.

8. Pahlevan AA, Ahmadpour-Qazvini F, Naserpour Farivar T, Johari P, Safdarian F, Najafipour R. Frequency of Helicobacter pylori in paraffin embedded blocks of chronic tonsillitis patients (2008-2009). J Qazvin Univ Med Sci 2012; 16(3): 19-25. [In Persian]

9. Baraldo S, Contoli M, Bonato M, Snijders D, Biondini D, Bazzan E, et al. Deficient immune response to viral infections in children predicts later asthma persistence. Am J Respir Crit Care Med 2018; 197(5): 673-5. doi: 10.1164/rccm.201706-1249LE.

10. Gozal D, Kheirandish-Gozal L. Disorders of breathing during sleep. In: Kendig's disorders of the respiratory tract in children. 9th ed. Philadelphia, W.B. Saunders; 2019. 1143-59.

11. Lindbaek M, Høiby EA, Lermark G, Steinsholt IM, Hjortdahl P. Clinical symptoms and signs in sore throat patients with large colony variant beta-haemolytic streptococci groups $\mathrm{C}$ or $\mathrm{G}$ versus group $\mathrm{A}$. Br J Gen Pract 2005; 55(517): 615-9.

12. Reis LG, Almeida EC, da Silva JC, Pereira Gde A, Barbosa Vde F, Etchebehere RM. Tonsillar hyperplasia and recurrent tonsillitis: clinical-histological correlation. Braz J Otorhinolaryngol 2013; 79(5): 603-8. doi: 10.5935/1808-8694.20130108.

13. Ezzeddini R, Gasemi B, Ghojazaded M, Darabi M. Histopathological examination of tonsillar tissue in 1250 children, Tabriz-Iran. J Gorgan Univ Med Sci 2013; 15(2): 90-3. [In Persian]

14. Nes WD. Biosynthesis of cholesterol and other sterols. Chem Rev 2011;111(10):

6423-51. doi: 10.1021/cr200021m.

15. Du SY, Wang HJ, Cheng HH, Chen SD, Wang LH, Wang WC. Cholesterol glucosylation by Helicobacter pylori delays internalization and arrests phagosome maturation in macrophages. J Microbiol Immunol Infect 2016; 49(5): 636-45. doi: 10. 1016/j.jmii.2014.05.011.

16. Kabouridis PS, Janzen J, Magee AL, Ley SC. Cholesterol depletion disrupts lipid rafts and modulates the activity of multiple signaling pathways in $\mathrm{T}$ lymphocytes. Eur $\mathrm{J}$ Immunol 2000; 30(3): 954-63.

17. De Sanctis JB, Blanca I, Rivera H, Bianco NE. Expression of low-density lipoprotein receptors in peripheral blood and tonsil $\mathrm{B}$ lymphocytes. Clin Exp Immunol 1998; 113(2): 206-12. doi: 10.1046/j.1365-2249. 1998.00579.x

18. Zong J, Liu Y, Huang Y, Chen J, Gao L, Zhang C, et al. Serum lipids alterations in adenoid hypertrophy or adenotonsillar hypertrophy children with sleep disordered breathing. Int $\mathbf{J}$ Pediatr Otorhinolaryngol 2013; 77(5): 717-20. doi: 10.1016/j.ijporl. 2013.01.025.

19. Ezzedini R, Darabi M, Ghasemi B, Darabi M, Fayezi S, Moghaddam YJ, et al. Tissue fatty acid composition in obstructive sleep apnea and recurrent tonsillitis. Int J Pediatr Otorhinolaryngol 2013; 77(6): 1008-12. doi: 10.1016/j.ijporl.2013.03.033.

20. Ezzeddini R, Darabi M, Ghasemi B, 
Jabbari Moghaddam Y, Jabbari Y, Abdollahi $\mathrm{S}$, et al. Circulating phospholipase-A2 activity in obstructive sleep apnea and recurrent tonsillitis. Int $\mathrm{J}$ Pediatr Otorhinolaryngol 2012; 76(4): 471-4. doi: 10.1016/j.ijporl.2011.12.026.

21. Chadha NK. Brodsky and Friedman scales and clinical tonsil size grading in children-reply. JAMA Otolaryngol Head Neck Surg 2015; 1. doi: 10.1001/jamaoto. 2015.2059.

22. Brufau G, Codony R, Canela MA, Rafecas M. Rapid and quantitative determination of total sterols of plant and animal origin in liver samples by gas chromatography. Chromatographia 2006; 64(9): 559-63. doi: 10.1365/s10337-0060034-4
23. Crane JM, Tamm LK. Role of cholesterol in the formation and nature of lipid rafts in planar and spherical model membranes. Biophys J 2004; 86(5): 2965-79. doi: 10. 1016/S0006-3495(04)74347-7.

24. Tall AR, Yvan-Charvet L. Cholesterol, inflammation and innate immunity. Nat Rev Immunol 2015; 15(2): 104-16. doi: 10.1038/ nri3793.

25. Lin CJ, Lai CK, Kao MC, Wu LT, Lo UG, Lin LC, et al. Impact of cholesterol on disease progression. Biomedicine (Taipei) 2015; 5(2): 7. doi: 10.7603/s40681-0150007-8.

26. Sun S, Cheng B, Wu X, Wu Q, Qi B, Wu $\mathrm{J}$, et al. Chlamydia pneumoniae disrupts lipid metabolism in human umbilical vein endothelial cells. Mol Med Rep 2014; 10(2): 1150-6. doi: 10.3892/mmr.2014. 2295. 